\title{
Explicit discrete fracture network numerical analyses of the stability of underground stopes and effects of cable bolt support at Raglan Mine
}

T Lavoie Andrieux \& Associates Geomechanics, L.P., Canada

P Andrieux Andrieux \& Associates Geomechanics, L.P., Canada

S Guido Andrieux \& Associates Geomechanics, L.P., Canada

R Caumartin Glencore, Canada

\begin{abstract}
Within the frame of the 2018 feasibility study of the Raglan Mine Mining Project 14 in northern Quebec, stability analyses of longhole stopes and the effects of cablebolting were conducted in the form of advanced three-dimensional discrete fracture network (DFN) simulations.

DFN analyses examine, in an explicit manner, the potential for strata to loosen and unravel, and wedges to form and fall along various excavation surfaces due to local joint sets. A DFN model is a randomly generated explicit representation of a unique set of discrete fractures whose geometrical characteristics-in terms of orientation, spacing and persistence-honour the statistical description of the joint sets present in the local rock mass. The kinematic stability of that unique situation is then examined in a direct manner with the 3D discontinuum-based 3DEC numerical code. Since each DFN model, or 'realisation', is randomly generated and unique, multiple realisations are required to derive statistical confidence in the outcome.
\end{abstract}

This paper describes the DFN methodology, discusses two means of populating a realisation (through the joint sets statistics or by 'bootstrapping' the characterisation data), introduces the velocity-based stability criterion retained for the analyses, and presents and compares results, with and without tendon ground support.

Keywords: numerical modelling, discrete fracture network, support design

\section{Introduction}

Within the frame of the feasibility study of the Glencore Canada Raglan Mine Mining Project 14 (MP14), located on the eastern limb of the Raglan property in northern Quebec, Canada, Glencore aimed to validate preliminary stope dimensions and cablebolting patterns. As part of this work, numerical discontinuum-based structural analyses of the back and walls of typical sample longhole and cut-and-fill stopes were undertaken. These focused on investigating the potential for strata to loosen and unravel, and wedges to form and fall along various excavation surfaces due to local joint sets, with and without artificial tendon ground support. These investigations were conducted through the discrete fracture network (DFN) approach that constitutes the topic of this paper.

\section{Geology}

The mineralisation at Raglan consists of sulphide lenses associated with Proterozoic ultramafic flows that lie along the contact of tholeiitic basalts and sediments of the Povungnituk Group and komatiitic basalts of the Chukotat Group within the Labrador Trough.

Nine peridotitic flows contain significant mineralisation over $55 \mathrm{~km}$. The ultramafic bodies contain sulphide mineralisation, mostly in the form of pentlandite and pyrrhotite, but also contain chalcopyrite, magnetite and pyrite with associated cobalt and platinum-group metals. 
The ultramafic package of MP14 is typically peridotitic in composition with lesser olivine pyroxenite and pyroxenite along the edges. The most prominent feature of the geology of MP14 is the ' $U$ ' shape of ultramafic rocks wrapped around a gabbro plug. There are four main geotechnical units in the MP14 area: gabbro (underlying formation), olivine pyroxenite, ore, peridotite and volcanics (overlying formation).

Based on information collected thus far, no large-scale faults have been identified in the MP14 area.

\section{Discrete fracture network methodology}

A DFN model is an explicit representation of joint sets within a given volume of rock. Since there is variability in the joint sets, multiple DFN 'realisations' are generally done, each one unique and representing a set of randomly generated explicit discrete fractures whose geometrical characteristics-orientation, spacing and persistence-honour the statistical description of the local joint sets. The kinematic stability of each realisation is then simulated with a discontinuum-based numerical code that considers the mechanical properties of the fractures. Since each realisation is generated randomly, the more realisations that are launched, the more reliable the statistical confidence in the outcome becomes. For example, if out of 100 realisations the situation is unstable in 20 cases, then a $20 \%$ probability of failure can confidently be assigned to the situation.

\section{$4 \quad$ Numerical code selection}

The structurally controlled dislocation and unravelling to be expected around the MP14 excavations and within abutting pillars were examined in detail with the explicit discontinuum-based distinct element 3DEC package (Itasca 2017), an advanced three-dimensional non-linear numerical code that can explicitly account for the effects of multiple discontinuities. Discontinuous materials are represented in $3 D E C$ by convex or concave polyhedral element assemblages within a three-dimensional grid. Individual blocks may be rigid or deformable - if deformable, these blocks are then zoned and made to behave according to a prescribed linear or non-linear stress-strain law in response to applied forces and boundary restraints. Discontinuities are treated as boundary conditions between the constitutive blocks. Motions along discontinuities are governed by linear and non-linear force-displacement relations for movements in both the normal and shear directions. A useful feature of $3 D E C$ is that discontinuity patterns can be constructed based on statistical distributions. Also, 3DEC employs an explicit time-marching solution algorithm that accommodates both large displacement and rotation, and permits time-domain calculations. The code provides the capability to explicitly represent the motion of multiple intersecting discontinuities, allows finite displacements and rotations of discrete bodies (including complete detachment) and automatically recognises new contacts as the calculation progresses.

Various types of discontinuous analyses are possible with 3DEC. The individual constitutive blocks can be made rigid, which results in an analysis whereby the discrete constitutive blocks cannot deform and, hence, cannot build internal stresses and fail. This approach, which involves quicker run times, can be used when the interest lies in analysing the kinematic behaviour of a blocky system under relatively low stress levels, whereby low confinement is conducive to a loosening of the strata and blocks between the discontinuities. In this case, the only required mechanical properties are those of the interfaces between the rigid blocks. The individual constitutive blocks can also be made deformable, in which case they must be zoned. These blocks can then deform, build internal stresses and eventually fail. With this method, the mechanical properties of the rock material(s) and of the interfaces between the discrete blocks are required as inputs. This approach, which requires significantly more computing power, is generally used for blocky systems subjected to high stress levels (typically in deep mining and/or high extraction ratio situations in blocky rock masses), or when artificial ground support needs to be modelled. 


\section{Joint characteristics assignment methods}

The DFN methodology requires the random generation of joint sets within a volume of rock, which are characterised by their dip angle, dip direction (or azimuth) angle, spacing and persistence, and need to ultimately reproduce the actual fracture density of the rock mass, as established from the site characterisation work. There are essentially two ways to randomly assign dip and dip direction to joints: one is based on the joint sets statistics, the other on 'bootstrapping'.

\subsection{The bootstrapping approach}

Bootstrapping is a resampling technique whereby actual data from the collected samples are directly used to generate the values necessary for the analyses. In simple terms, one could imagine bootstrapping as writing down on individual cards all the data available for each joint sampled during the characterisation campaign: one card per observed joint. The cards are then put in a bag and, each time a new joint is generated in the $3 D E C$ model, its dip and dip direction are determined by randomly drawing a card from the bag and using the information on it. Since the dip and dip direction for the joint to be generated in the model now come from an actual surveyed joint, all the other information logged for that joint - its shape (planar, undulating, stepped), aperture and infilling - can also be readily used to populate the various other characteristics required in the model, including strength properties. The card is then put back into the bag and the process is repeated until enough fractures have been generated to reproduce the fracture frequency observed in the boreholes, or the one sought in the analysis. Uncertainty in the dip and dip direction is accounted for by allowing a deviation, typically between +5 and $-5^{\circ}$, randomly selected from a uniform distribution. The resulting values are then retained as joint inputs to the DFN model.

\subsection{Sampling bias}

As it is the case for the joint sets approach, bootstrapping can be affected by sampling bias. Sampling bias is the under-representation of joints of a certain orientation relative to the orientation of the observation hole. As illustrated in Figure 1, when logging is conducted for example in a vertical hole, there is little chance it will miss any sub-horizontal joints it will intersect (Figure 1a). However, that hole will only encounter a limited number of sub-vertical joints, which will result in them being under-sampled in the dataset (Figure 1b).

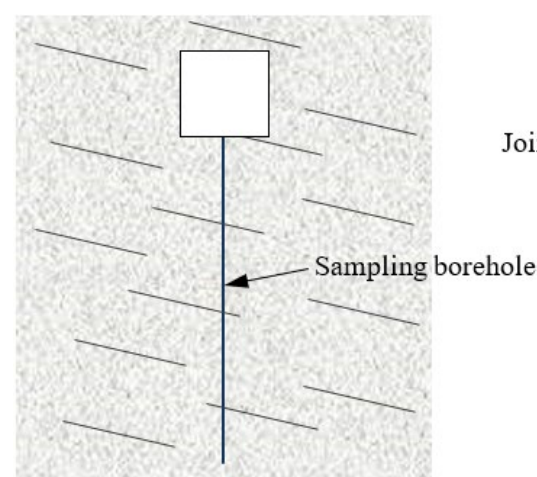

(a)

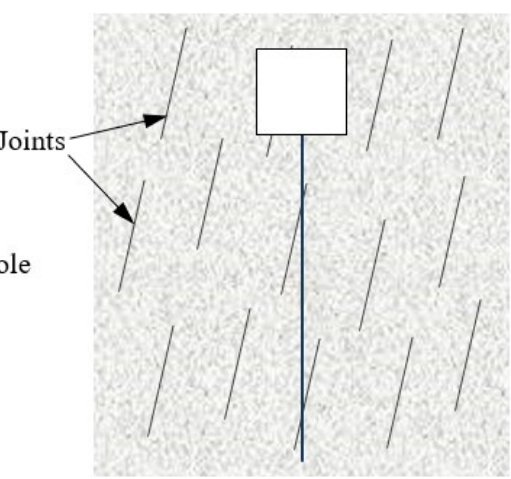

(b)

Figure 1 Sampling bias due to the orientation of the joint sets relative to that of the observation borehole. (a) Proper sampling of the joints; (b) Under-sampling of the joints

The approach suggested by Palmström (1996) can be used to correct for sampling bias. The weighted joint density method he developed consists in dividing the logged joints into four groups based on their intersection angle with the borehole (Table 1). Each group is then assigned a rating factor, which is a scaling value meant to account for the under-sampling of joints intersecting the borehole at a steep angle. For example, a joint with an intersection angle of less than $16^{\circ}$ with the borehole has six times more chances of being sampled than a joint with an intersection angle of more than $60^{\circ}$. That rating factor can then be used to adjust the probability of selecting a joint in the bootstrapping process. 
Table 1 Angles and rating factors for the weighted joint density method (after Palmström 1996)

\begin{tabular}{lc}
\hline Angle between joint and borehole (deg.) & Rating factor \\
\hline More than 60 & 1.0 \\
31 to 60 & 1.5 \\
16 to 30 & 3.5 \\
Less than 16 & 6.0 \\
\hline
\end{tabular}

Figure 2 compares the uncorrected (Figure 2a) and corrected (Figure 2b) stereonets for all the joints sampled for MP14: the sampling bias can clearly be seen in the uncorrected stereonet on the left.
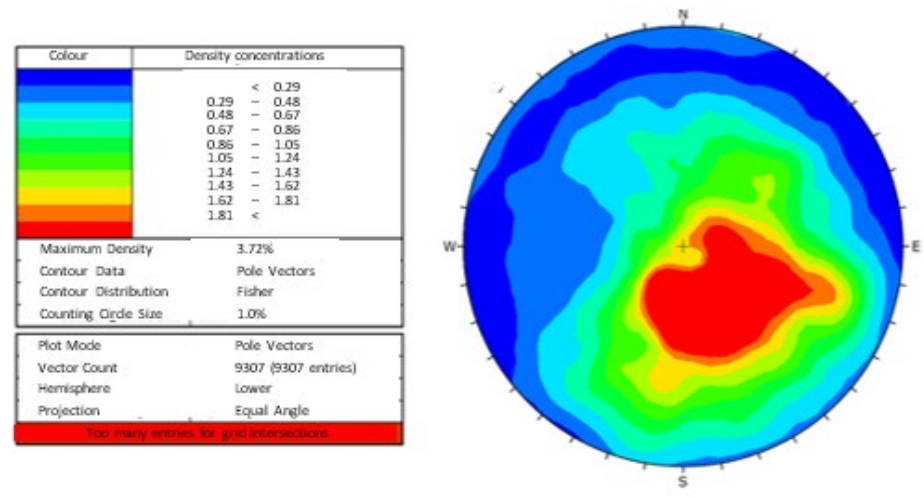

(a)

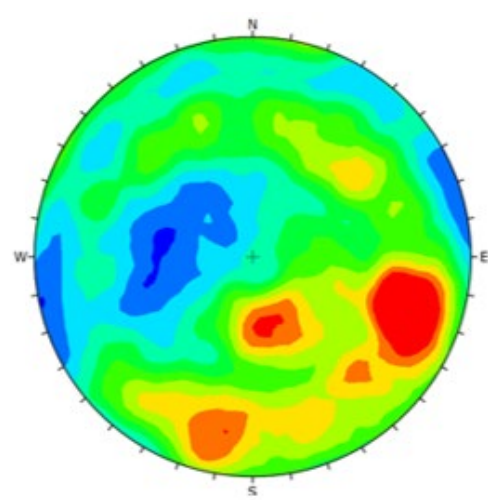

(b)

Figure 2 Stereonets showing contour plots for all the joints sampled for MP14. (a) Uncorrected data; (b) Corrected data

When the holes used for the structural characterisation are near-parallel, some bias can be expected to remain despite correction - as a result, it is always preferable to sample joints with boreholes at different angles in order to capture as many joints as possible. Regardless of how efficient correction methods can be, they can never replace a well-sampled dataset.

\section{Joint characteristics in the DFN models}

This section discusses in more details how the geometrical characteristics (dip, dip direction, spacing and persistence) and mechanical properties were assigned to the individual joints in the DFN realisations.

\subsection{Joint orientation}

The dip and dip direction angles of each joint in the 3DEC models were obtained directly with the bootstrapping method from the joints randomly picked from those logged during the characterisation campaign, altered by a value between $+5^{\circ}$ and $-5^{\circ}$ randomly selected from a uniform distribution to add some variability.

\subsection{Joint spacing}

Joint spacing was not a construction parameter per se: instead of trying to reproduce joint spacing, fracture frequency was controlled (both represent the same parameter, fracture frequency being the inverse of joint spacing). Fracture frequency was adjusted by continuing to add joints until enough fractures were generated to reproduce the fracture frequency observed in the corresponding boreholes (an average over five virtual boreholes was used). 


\subsection{Joint persistence}

Assuming a power law distribution, the number of fractures of a given length per unit volume can be expressed as follows:

$$
N(I)=\alpha \times I^{-a}
$$

where:

$$
\begin{aligned}
& \alpha \quad=\text { fracture density. } \\
& \mathrm{L} \quad=\text { fracture persistence. } \\
& \mathrm{a} \quad=\text { scaling component that controls the ratio between larger and smaller fractures. }
\end{aligned}
$$

The scaling component $a$ was set, in the case of the MP14 analyses, to a value of three for all simulations whereas the fracture frequency was selected, based on the televiewer data from all eight available test holes, at 1.6 fracture per metre. Given these parameter settings, Equation 1 allowed to establish the persistence $I$ of the bootstrapped fractures. Previous experience at Raglan in similar geologies was used to assist in establishing persistence ranges: for each joint generated in the models, a persistence value was randomly selected from the power law distribution of Equation 1 using the persistence shown in Table 2.

Table 2 Persistence properties for the DFN analyses

\begin{tabular}{llc}
\hline Structure & Shape & Persistence $(\mathbf{m})$ \\
\hline \multirow{2}{*}{ Closed (96\% of the data) } & Planar & 3 to 10 \\
& Discontinuous & 3 to 10 \\
& Planar & 10 to 20 \\
Fractured, open, or & Undulating & 10 to 20 \\
slightly open (4\% of the data) & Irregular & 10 to 20 \\
& Discontinuous & 10 to 20 \\
\hline
\end{tabular}

\subsection{Joint strength properties}

When selecting with the bootstrapping method a joint from a collection of logged joints, all the information related to that particular fracture can also be retrieved, including on its shape (planar, undulating, stepped), aperture and infilling, which largely control its strength properties. The unfiltered raw televiewer data included planar, undulating, irregular, stepped and discontinuous fracture shapes (discontinuous joints are joints that partially intersected the borehole), both open and closed.

The computational power currently available does not allow DFN models, of the size considered in this study, to be run within the time frame of a typical consulting project while representing all joints logged with the televiewer (open, closed, irregular, planar, etc.). Consequently, informed engineering knowledge must be used to filter out some of the joints that have a smaller probability to impact the stability of the excavation.

Closed undulating and irregular fractures can be expected to exhibit significantly higher frictional strength compared to planar fractures, requiring greater rock mass dilation before they become unstable. As an example, Ghani Rafek \& Goh (2012) derived an equation linking the Joint Roughness Coefficient (JRC) to the peak friction angle of joints $\phi_{\text {peak }}$ for the schists they studied using rock blocks containing natural discontinuity planes:

$$
\phi_{\text {peak }}=\left(-0.022 \times J R C^{2}\right)+(3.21 \times J R C)+28.1
$$

where:

$$
\begin{aligned}
& \phi_{\text {peak }}=\text { peak friction angle. } \\
& \mathrm{JRC}=\text { joint roughness coefficient. }
\end{aligned}
$$


Using Equation 2 and assuming that undulating and irregular joints have a JRC of 10 and 16, respectively, it can be calculated that the peak friction angle for an undulating joint would be about $58^{\circ}$ while that of an irregular joint would be around $74^{\circ}-$ for reference, a planar joint with a JRC of four would have a friction angle of about $40^{\circ}$, for the schists studied by Ghani Rafek \& Goh. Actual values for Raglan are expected to be different, however they should follow a similar trend.

Raw televiewer data were therefore processed using Dips $^{\text {TM }}$ version 6.0 (Rocscience 2015), with closed undulating and irregular fractures being eliminated from the dataset because of their potential limited influence on kinematic instability. Compare Figure 3a, which shows the stereonet with all the joints, with Figure 3b, which shows only the open, planar and discontinuous joints. Note how the steeper joint sets gained in importance when filtering out the closed, undulating and irregular joints, and how the more horizontal joint set lost in importance. This observation, that the steeper joint sets has a greater chance to form unstable blocks while the more horizontal joint sets affects less the stability, correlates well with observations made at the mine.

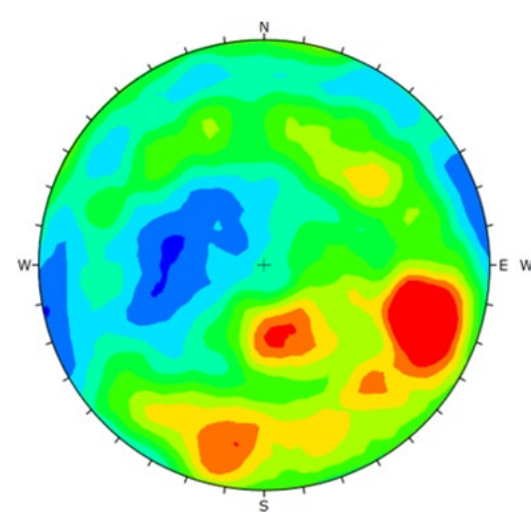

(a)

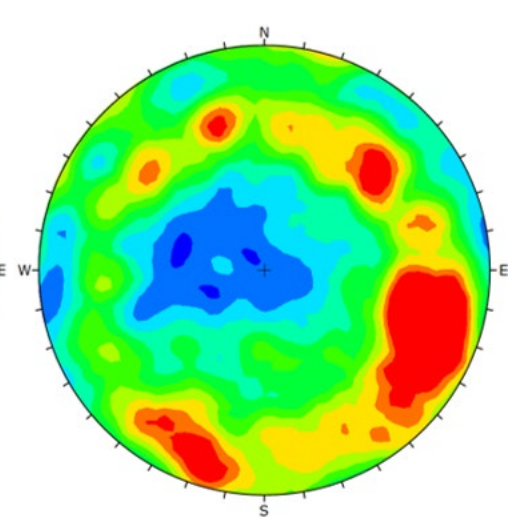

(b)

Figure 3 Stereonet of all the joints in the eight boreholes surveyed, with correction for sampling bias (a), versus stereonet of only open, planar and discontinuous joints in the same eight boreholes, also with correction for sampling bias (b)

In an effort to represent the rock mass as accurately as possible, the structural data was first broken by lithological units, in terms of ore material to study interim stope backs and walls and remnant pillars, and host rock material to study final stope backs and abutments. However, the main joint sets were found in all the geotechnical units in the MP14 lenses, suggesting that the structural geology is more or less homogeneous across all lithologies. Furthermore, the data, with only 221 entries for the ore (considering only planar, open and discontinuous joints), were deemed statistically insufficiently representative (Figure 4).
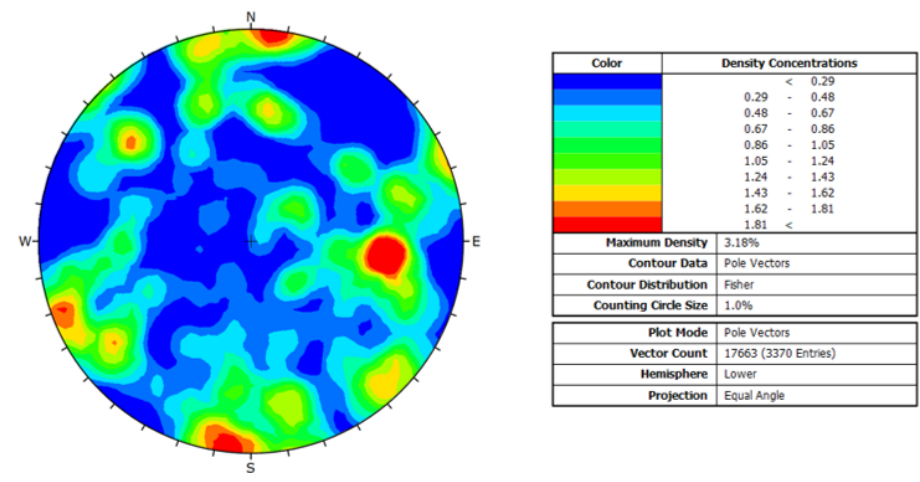

Figure 4 Stereonet of the planar, discontinuous and open joints for the ore material only, corrected for sampling bias 
Therefore, all the joints surveyed in the ore, hanging wall and footwall units in the characterisation work were used in all the simulations. This approach was more conservative since it allowed more degrees of freedom in the $3 D E C$ models (more joint sets result in more distinct blocks) and was statistically sounder (using 3,370 data points instead of only 221).

Most of the DFN analyses were completed with rigid blocks, as this approach entails much quicker computer run times and was suitable in unsupported cases. As a result, the mechanical properties needed for these models revolved around those of the joints and discontinuities between the rigid blocks. Consequent to the bootstrapping approach implemented, the structural description associated with the joints picked during the process was used to assign the mechanical properties of these joints, based on aperture (closed versus open) and shape (planar, discontinuous, undulating or irregular). From results of direct shear tests, the peak friction angle was set at $40^{\circ}$ for closed planar joints (similarly to what was suggested by Eq. (2)), $43^{\circ}$ for closed discontinuous joints and only $35^{\circ}$ for all open joints. These values can be considered conservative (on the low side). Residual friction angle values were set to $35^{\circ}$ for all joints. No cohesion and no tensile strength were considered, to remain conservative by not over-estimating joint strength. Table 3 summarises the joint strength properties retained.

Table 3 Joint properties for the DFN analyses

\begin{tabular}{llccccc}
\hline \multirow{2}{*}{ Structure } & Shape & \multicolumn{3}{c}{ Friction angle (deg.) } & \multirow{2}{*}{ Cohesion } & \multirow{2}{*}{ Tension } \\
\cline { 3 - 6 } & & Peak & Variability +/- & Residual & & \\
\hline \multirow{2}{*}{ Closed (96\%) } & Planar & 40 & 5 & 35 & 0 & 0 \\
& Discontinuous & 43 & 3 & 35 & 0 & 0 \\
\cline { 2 - 5 } $\begin{array}{l}\text { Fractured, open, } \\
\text { or slightly open }\end{array}$ & Planar & 35 & 2 & 35 & 0 & 0 \\
(4\%) & Undulating & 35 & 2 & 35 & 0 & 0 \\
& Irregular & 35 & 2 & 35 & 0 & 0 \\
\hline & Discontinuous & 35 & 2 & 35 & 0 & 0 \\
\hline
\end{tabular}

Besides the strength properties described in Table 3, elastic properties were also required. When modelling rigid blocks, the stiffness of the system is captured through that of the interfaces between these rigid blocks. 'Equivalent' joint stiffness estimates can be made based on the assumption that the rock mass contains a set of uniformly spaced joints, which allows the following relation between rock modulus and joint normal stiffness to be used (Itasca 2017):

$$
k_{n}=\left(E_{m} \times E_{r}\right) /\left(s \times\left[E_{r}-E_{m}\right]\right)
$$

where:
$k_{n} \quad=$ joint normal stiffness.
$\mathrm{E}_{\mathrm{m}} \quad=$ rock's Young's modulus at the scale of the rock mass.
$\mathrm{E}_{\mathrm{r}} \quad=$ rock's Young's modulus at the scale of the intact rock material and $s$ is the joint spacing.

For the same assumptions, the relation between rock shear modulus and joint shear stiffness can be established, as follows (Itasca 2017):

$$
k_{s}=\left(G_{m} \times G_{r}\right) /\left(s \times\left[G_{r}-G_{m}\right]\right)
$$

where:
$k_{s} \quad=$ joint shear stiffness.
$\mathrm{G}_{\mathrm{m}}=$ rock's shear modulus at the scale of the rock mass.
$\mathrm{G}_{\mathrm{r}} \quad=$ rock's shear modulus at the scale of the intact rock material and $s$ is the joint spacing. 
Based on the available information from lab testing, a rock mass Young's modulus of $50 \mathrm{GPa}$, a shear modulus of $20 \mathrm{GPa}$ and, as mentioned previously, a fracture frequency of 1.6 fracture per metre were retained for this work.

\section{$7 \quad$ Rock mass properties}

In those analyses that required the blocks to be zoned - when artificial ground support was considered, which necessitates deformable blocks in order to bond the tendons to the rock mass over their entire length - the rock mass modulus was set as high as $200 \mathrm{GPa}$. This was done in order to simulate near-rigid blocks, to make it possible to compare the results of the zoned analyses to those of the rigid analyses. Making the zoned blocks very stiff made it necessary to keep the same elastic properties for their defining joints. As a result, the elastic properties of the joints that defined the zoned blocks in the host rock material where cable bolt effects were modelled were set at the same values as those that defined the rigid blocks of the unsupported analyses. Note that the applied stresses, from gravity alone, being insufficient to crush the rock mass matrix, the analyses were conducted elastically - hence, no rock mass strength properties needed to be derived.

\section{$8 \quad$ Model geometry}

As mentioned, the explicit stochastic DFN analyses were conducted on the back and walls of 'typical' stopes (representative stope geometries derived from the design shapes) and equally 'typical' pillar geometries (representative rib pillar geometries also derived from the design shapes). This paper will only discuss those analyses conducted on final longhole stope roofs (or backs), in waste material.

The geometry of various representative stopes was first isolated from the design shapes. Conservative stope geometries were then selected, which were subsequently idealised and built in smaller three-dimensional distinct element models with modular zones that could be assigned various structural characteristics, allowing each model to examine a range of cases. Only those representative sample stope geometries were analysed from the structural stability perspective. The geometry of panel $14 \mathrm{E}-10$ - shown in Figure 5 - was extracted from the $14 \mathrm{E}$ orebody and taken to represent a typical longhole stope in lenses $14 \mathrm{E}$ and $14 \mathrm{~F}$.

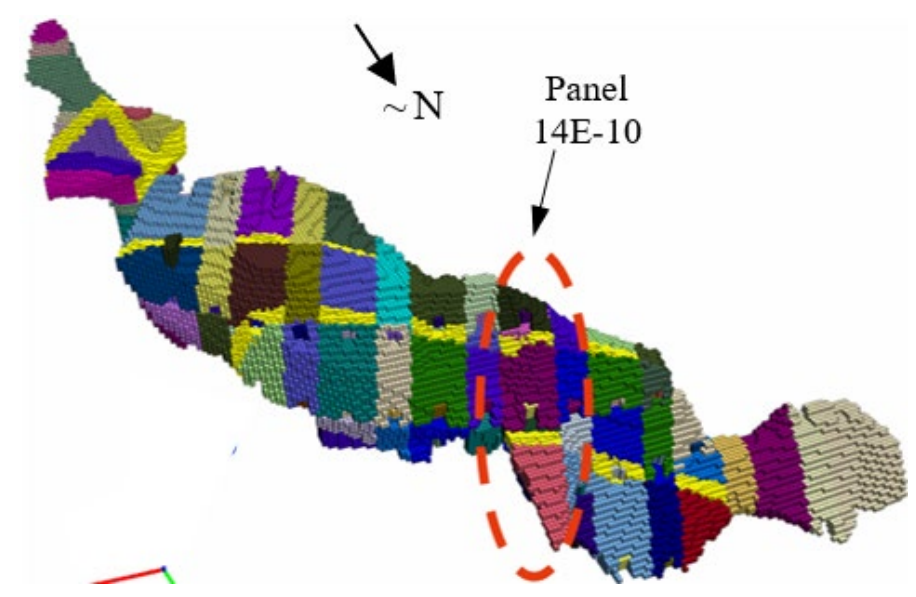

Figure 5 Isometric view of Lens 14E looking approximately southwest from above, showing the location of mining panel 14E-10 selected as representative of typical MP14 longhole stopes

Figure $6 a$ shows the actual $14 \mathrm{E}-10$ excavations, whereas Figure $6 \mathrm{~b}$ shows the idealised geometry used in $3 D E C$ for the DFN analyses. The excavations were $25 \mathrm{~m}$ wide as they were secondary stopes (wider secondary blocks were deliberately selected for their larger spans, for conservatism). 


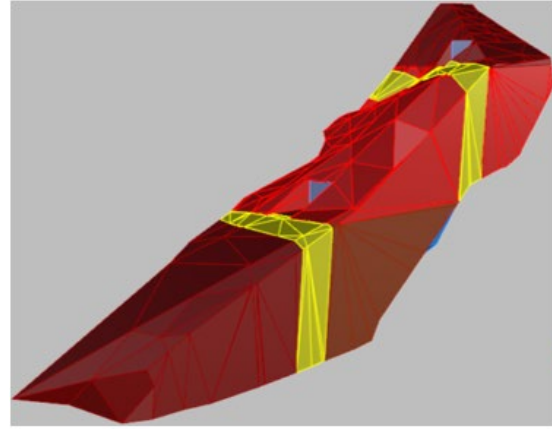

(a)

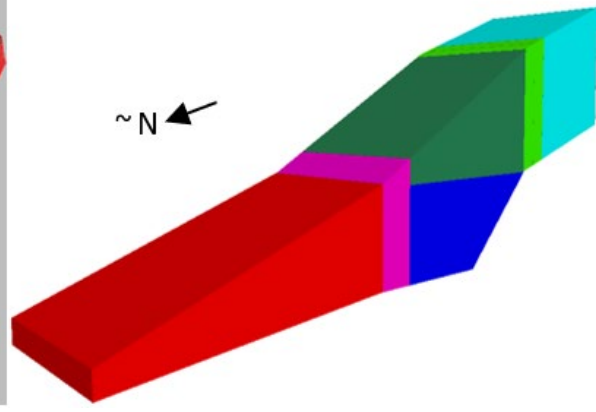

(b)

Figure 6 Isometric views of the 14E-10 mining panel looking approximately southeast from above. (a) Panel 14E-10; (b) Idealised panel 14E-10 on 3DEC

\section{Cable bolt properties and configuration}

Those simulations that examined the stabilising effects of cablebolting had discrete patterns of twin cablebolts inserted in the 3DEC models, and, hence, required the associated mechanical properties. These are summarised in Table 4. Note that the cablebolts were considered in all the simulations un-platted and un-tensioned.

Table 4 Cable bolt properties (for double cablebolts [2 cablebolts per hole])

\begin{tabular}{lc}
\hline Parameter (unit) & Value \\
\hline Cross-area $\left(\mathrm{mm}^{2}\right)$ & 280 \\
Cable modulus $(\mathrm{GPa})$ & 200 \\
Yield strength $(\mathrm{MPa})$ & 430 \\
Bond stiffness $\left(\mathrm{MN} / \mathrm{m}^{2}\right)$ & 30 \\
Bond strength $(\mathrm{kN} / \mathrm{m})$ & 230 \\
\hline
\end{tabular}

The cable bolt layout considered for the sample longhole stope final back models is shown in Figure 7 and Figure 8. It consisted of the upper section of the cablebolts drilled from the undercut drive that remained after blasting the stope, and the cablebolts installed from the overcut drive. The length of the cablebolts depended on their position along the roof since the installation holes did not all cross the back at the same location. Furthermore, the cablebolts installed from the overcut drive were designed to stop at the contact with the ore, the position of which varied along the length of the drive. Six rows of eight cablebolts were left from the undercut drive, and four rows of nine cablebolts were installed from the overcut drive. The spacing was $2.2 \mathrm{~m}$ between cable bolt rows.

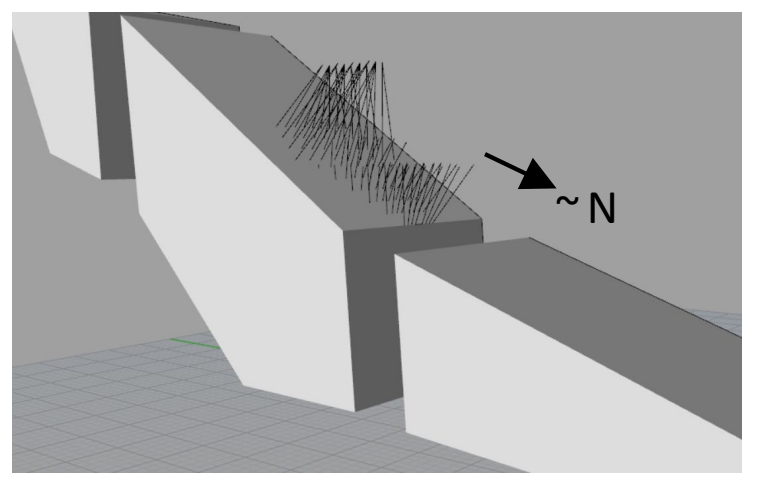

Figure 7 Isometric view looking approximately southwest showing the general cable bolt design in the roof of the longhole stopes 


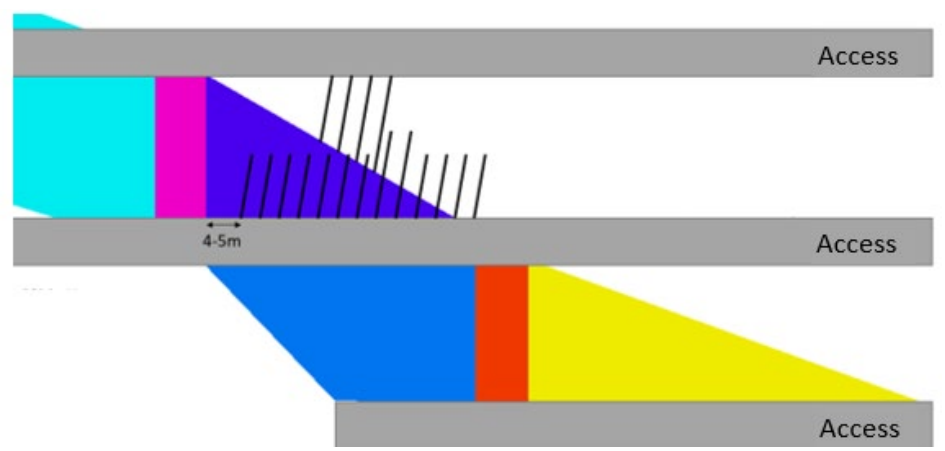

Figure 8 Cross-section looking approximately west showing the cable bolt design for the longhole stope backs

\section{Results of the analyses}

Since DFN modelling is a stochastic process, each outcome is different. For this reason, and in an effort to capture the full range of variability, 11 realisations were run for the unsupported models (without artificial ground support). Although running more models would have yielded more statistically significant results, the number of 11 was selected because it offered a good sample of the range of potential outcomes and allowed the models to be run within the time frame of this project. The worst case from these simulations (the most unstable realisation) was then selected to test the proposed ground support designs in the supported analyses.

\subsection{Stability criterion}

Prior to drawing conclusions from the modelling results, a stability criterion needs to be established to assess the onset of instability. After running the model for 10,000 cycles, moving blocks with velocities below $0.01 \mathrm{~m} / \mathrm{s}$ $(1 \mathrm{~cm} / \mathrm{s})$ were deemed stable given that their rate of displacement tended to abate as the number of cycles increased. On the other hand, blocks with velocities above that threshold either continued to move at the same rate or even accelerated. The velocity criterion proved to be a better indicator than acceleration as it was less erratic in the model and more consistently predicted unstable blocks early on in the modelling process.

This $1 \mathrm{~cm} / \mathrm{s}$ velocity-based criterion was verified for MP14 by further cycling a model over many steps, to ensure that volumes that would be deemed unstable much earlier in the simulation based on that velocity do in fact separate and fall away from the remaining stable blocks above. Figure 9 shows the results of that verification exercise for 10,000 (Figure 9a) versus 60,000 cycles (Figure 9b), for the cut-and-fill model (which is visually conducive to that comparison). As can be seen, the volume of unstable rock at 10,000 cycles, as inferred from that $0.01 \mathrm{~m} / \mathrm{s}$ velocity criterion (blocks coloured any colour other than dark blue), is comparable to the volume of rock detached from the roof and free-falling into the stope after 60,000 cycles. Based on this verification, the $1 \mathrm{~cm} / \mathrm{s}$ velocity criterion was retained for all the MP14 structural analyses.

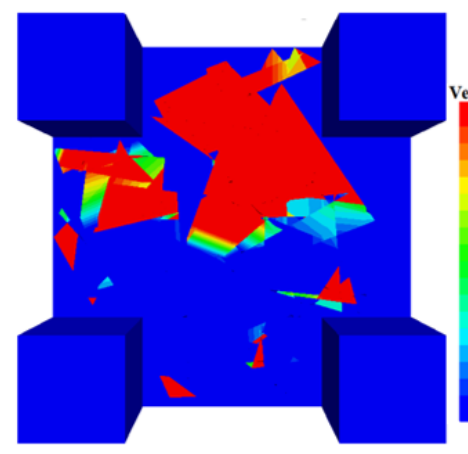

(a)

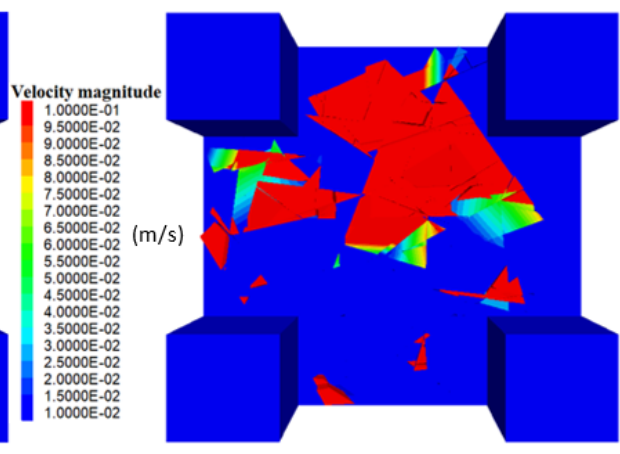

(b)

Figure 9 Views looking upwards at the roof of the 14B Lens sample cut-and-fill model, showing velocity plots for the verification of the $0.01 \mathrm{~m} / \mathrm{s}$ velocity stability criterion. (a) At 10,000 cycling steps; (b) At 60,000 cycling steps 


\subsection{Behaviour of the unsupported longhole stope final roof}

Figure 10a shows the total volume of unstable blocks computed for each of the 11 realisations launched, and Figure $10 \mathrm{~b}$ shows the depth of failure for the deepest unstable wedge in each realisation. It can be seen that the volume of unstable blocks varied between 175 (for realisation 8) and over $500 \mathrm{~m}^{3}$ (for realisation 4). The depth of failure of the deepest wedges varied between 2.75 (for realisation 8) and $5.10 \mathrm{~m}$ (for realisation 4). Figure $11 \mathrm{a}$ and Figure $11 \mathrm{~b}$ show unstable blocks for the most unstable realisation, in plan view and in cross-section, respectively. These results suggest that, although some instability is observed in the unsupported models, unstable blocks in the final inclined roofs should be manageable once properly supported.

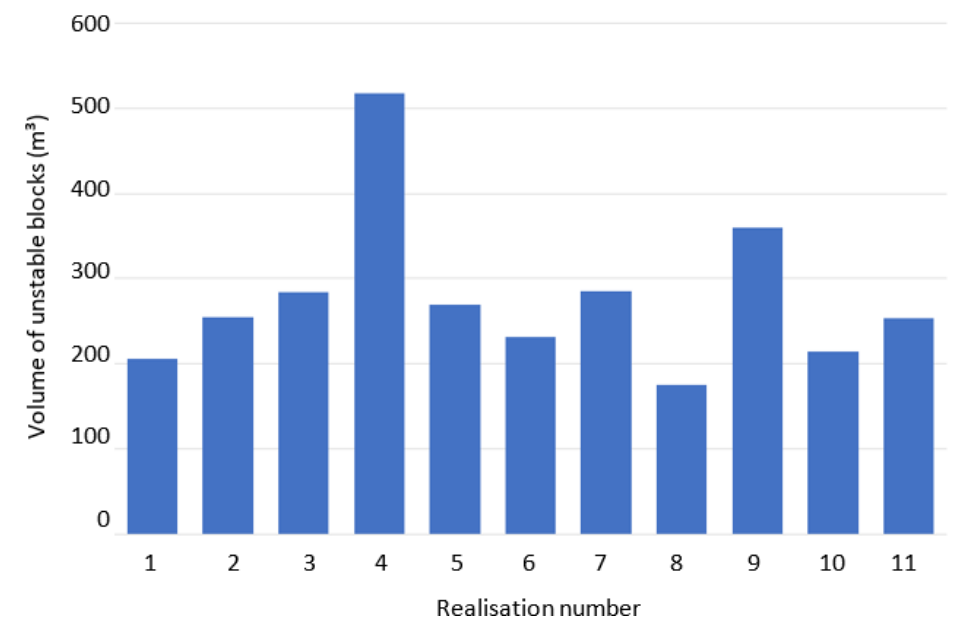

(a)

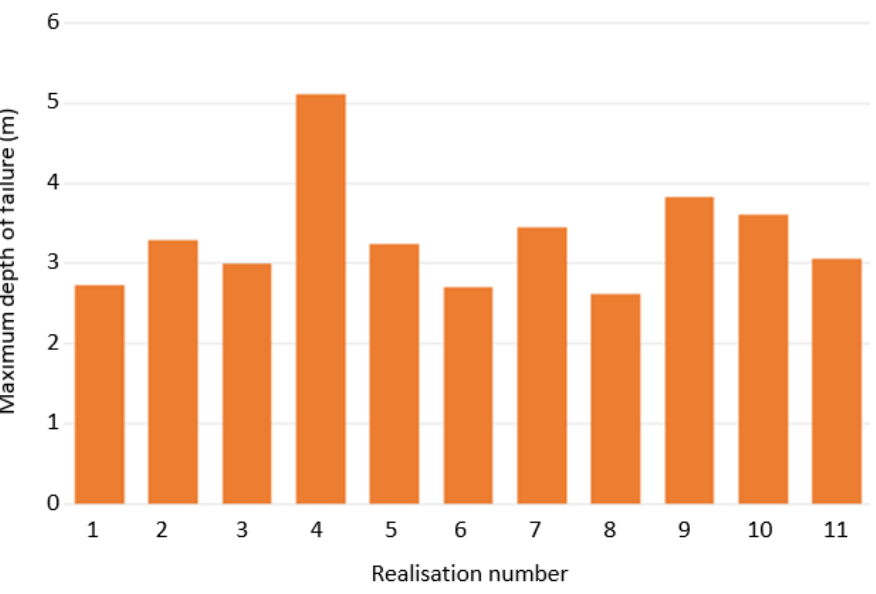

(b)

Figure 10 Histograms showing (a) the total volume of unstable blocks and (b) depth of failure of the deepest unstable wedges in the final roof of the longhole stope model for each realisation 


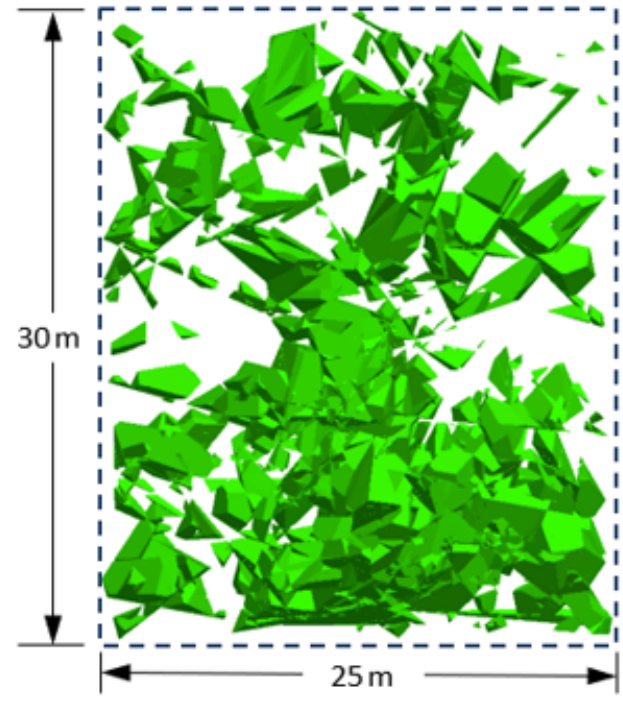

(a)

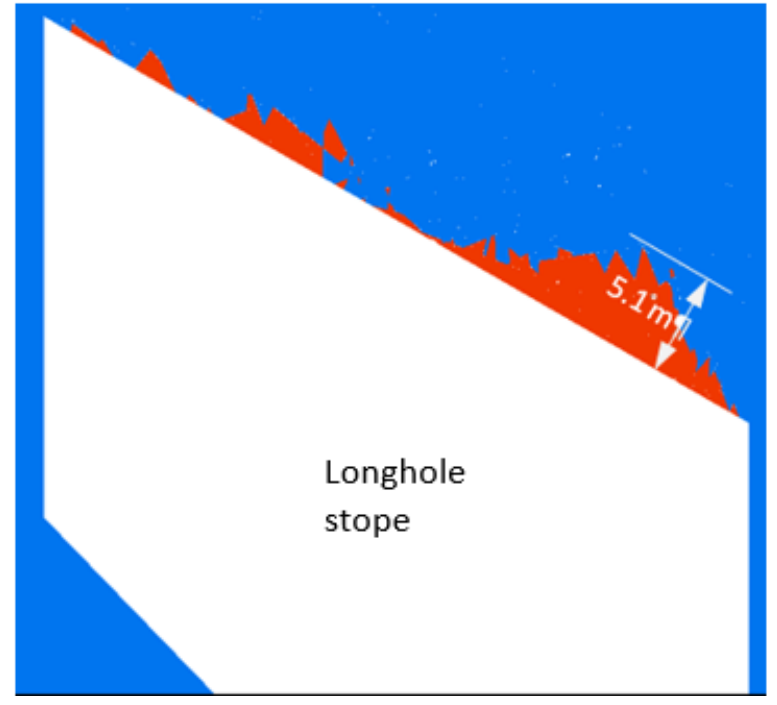

(b)

Figure 11 Orthogonal plan view showing (in green) unstable blocks (a) and cross-section showing (in red) unstable blocks (b), in the final roof of the longhole stope model for realisation 4 , the most unstable realisation

\subsection{Behaviour of the supported longhole stope final roof}

The most unstable realisation from the unsupported models (realisation 4) was retained to test the effectiveness of the proposed cable bolt support design. Realisation four was thus rerun, but this time zoned and with cablebolts added to the model based upon the guidelines presented in Section 8. Figure 12 shows a comparison between the total volume of unstable blocks and the depth of failure of the deepest wedges for the unsupported versus supported situations. Figure 13 shows a comparative plan view of the unstable blocks from the unsupported and supported models. These figures clearly show that the support can be expected to be highly effective at limiting the unravelling of the blocks in the final roof to only a small number of wedges located between the support tendons.

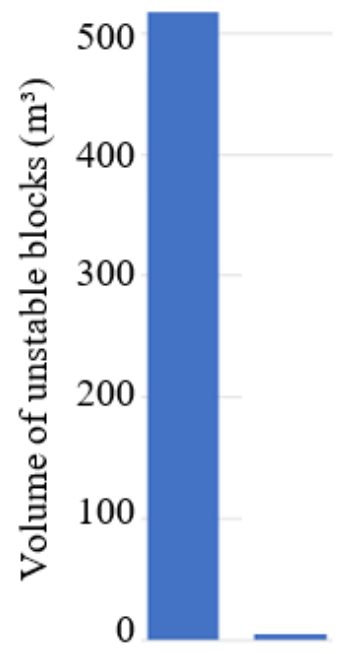

Unsupported Supported

(a) Total unstable volume.

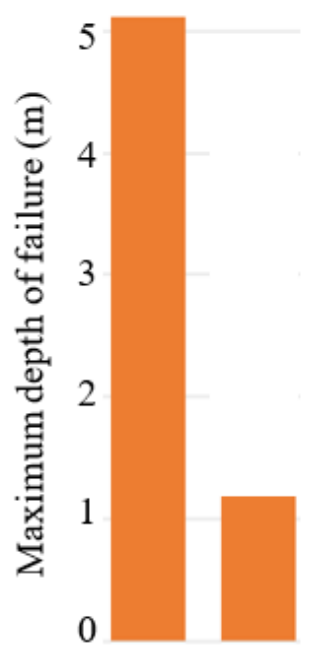

Unsupported Supported

(b) Deepest unstable wedges.

Figure 12 Histograms showing the total volume of unstable blocks and the depth of failure of the deepest unstable wedges in the longhole stope final roof models for realisation 4 , (a) without and (b) with (b) cablebolts 


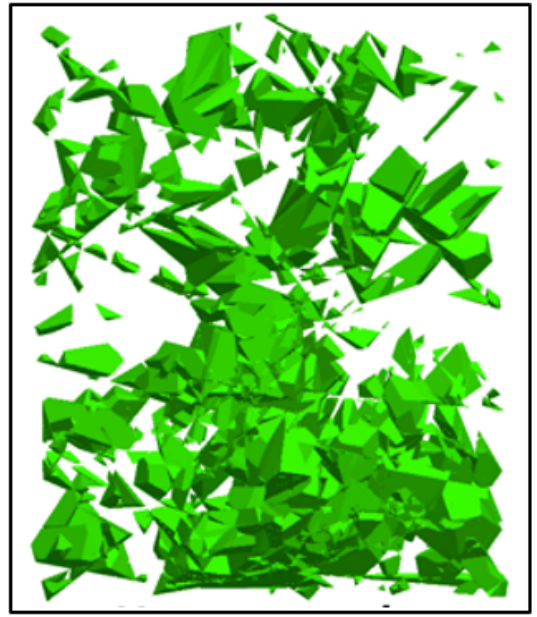

(a)

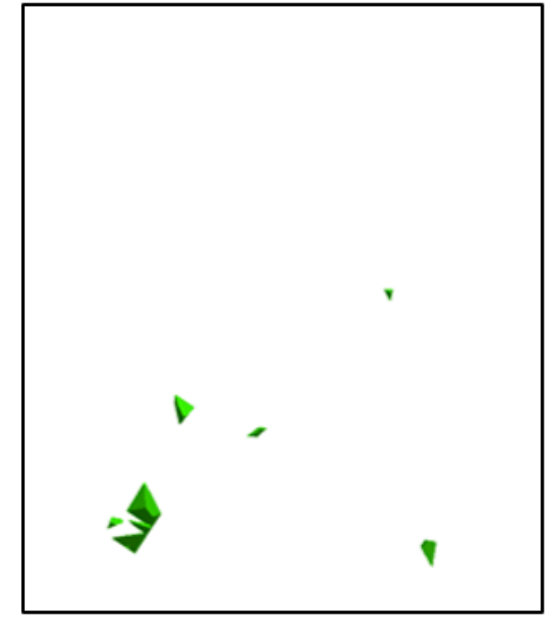

(b)

Figure 13 Orthogonal plan views showing (in green) unstable blocks in the final roof of the longhole stope final roof models for realisation 4 , (a) without cablebolts and (b) with cablebolts

Figure 14 shows the axial forces developed in the cablebolts at equilibrium. The loads in the cables do not exceed $40 \mathrm{kN}$ (four tonnes), which is well below even their elastic capacity. A scale from 0 to $40 \mathrm{kN}$ has been used for this figure so the forces acting in the cables are clearly visible. Red contours on the cables are well below the cables' capacity and thus does not indicate failure.

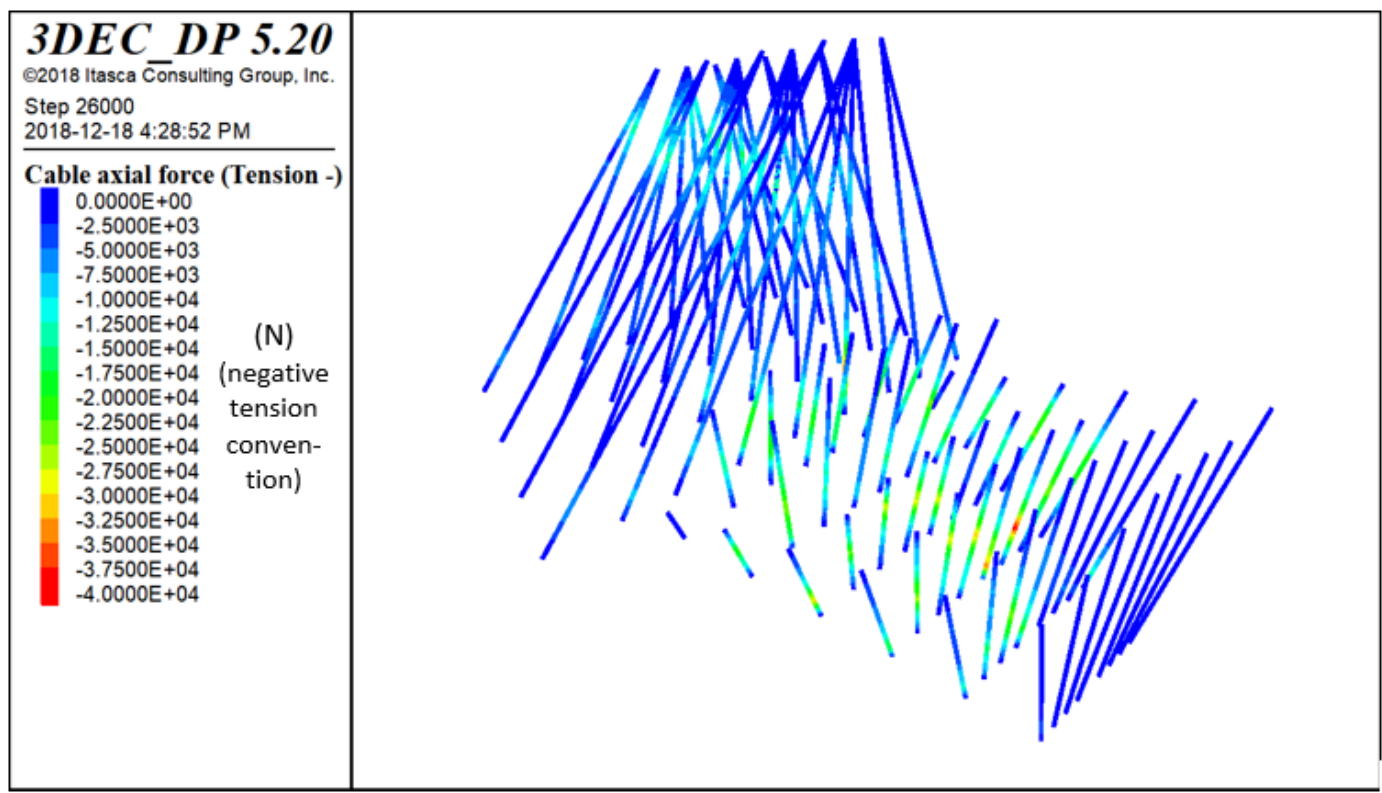

Figure 14 Axial forces in the cablebolts of the supported longhole stope final roof model, at equilibrium, for realisation 4

These results suggest that, even though some instability is still observed in the supported model, unstable volumes are drastically reduced and unstable blocks in the final longhole stope roofs should be largely managed once cablebolted.

\section{Conclusion}

Overall, the breakout profiles and depths of failure predicted for the MP14 excavations were generally comparable to what has been historically observed at Raglan, which lends credibility to the results. The unsupported longhole stope roof models showed that, while some sizeable blocks were unstable, these 
surfaces generally behaved well, even without cablebolts. The cablebolted longhole stope roof analyses confirmed the anticipated effectiveness of the proposed secondary support system. The volume of unstable blocks was drastically reduced from as much as over $500 \mathrm{~m}^{3}$ to less than $10 \mathrm{~m}^{3}$, whereas the depth of failure decreased from over 5 to just over $1 \mathrm{~m}$. Axial forces in the cablebolts at equilibrium also stayed well below their elastic capacity.

Notes: $3 D E C$ is a registered trademark of Itasca Consulting Group, Inc., Minneapolis, MN, USA. DIPS is a registered trademark of Rocscience, Inc., Toronto, ON, Canada.

\section{References}

Ghani Rafek, A \& Goh, T 2012, 'Correlation of joint roughness coefficient (JRC) and peak friction angles of discontinuities of Malaysian schists', Earth Science Research, 10.5539/ESR, vol. 1, no. 1, pp. 57-63.

Itasca 2017, 3DEC Version 5.20 - Theory and Background, Itasca Consulting Group, Inc., Minneapolis.

Palmström, A 1996, 'The weighted joint density method leads to improved characterization of jointing', Proceedings of the Conference on Recent Advances in Tunnelling Technology, pp. 1-6.

Rocscience 2015, DIPS Version 6 User's Manual, Rocscience, Inc., Toronto. 